\title{
Alexithymia predicts maladaptive but not adaptive emotion regulation strategies in adolescent girls with anorexia nervosa or depression
}

\author{
Anca Sfärlea ${ }^{1 *}$, Sandra Dehning ${ }^{1 \dagger}$, Lena Katharina Keller ${ }^{1,2}$ and Gerd Schulte-Körne ${ }^{1}$
}

\begin{abstract}
Background: Among adolescent girls, anorexia nervosa (AN) and major depression (MD) are common and often comorbid mental health problems. Both disorders are characterised by difficulties in recognising and verbalising (alexithymia) as well as regulating one's emotions, but research in adolescent patients is scarce and little is known about the relation between alexithymia and difficulties in emotion regulation. The aims of this study were to investigate alexithymia and emotion regulation skills in adolescents with AN, adolescents with MD, and healthy adolescents, and to determine whether alexithymia functions as a predictor for emotion regulation skills.

Methods: Emotion regulation strategies, alexithymia, and depressive symptoms were assessed by questionnaire measures in 12-18 year old girls with AN $(n=26)$, girls with MD $(n=25)$, and healthy girls $(n=35)$. Groups were compared with respect to the these variables and multiple regression analyses were calculated separately for adaptive and maladaptive emotion regulation strategies in order to examine if alexithymia predicted emotion regulation over and above age and depressive symptoms.

Results: Girls with AN or MD both reported using adaptive emotion regulation strategies less frequently and maladaptive emotion regulation skills more frequently as well as higher levels of alexithymia compared to healthy girls. Alexithymia positively predicted maladaptive emotion regulation strategies, while depressive symptoms negatively predicted adaptive emotion regulation strategies.

Conclusions: The results suggest that different mechanisms may underlie the lack of adaptive and the surplus of maladaptive emotion regulation strategies in adolescent psychiatric patients.
\end{abstract}

Keywords: Adolescence, Emotion regulation, Alexithymia, Anorexia nervosa, Major depression

\section{Plain English summary}

Anorexia nervosa and major depression are common mental health problems among adolescent girls. Many people who suffer from these disorders also have difficulties dealing with their emotions: they struggle recognising and talking about their emotions (a psychological characteristic called "alexithymia") as well as regulating their emotions appropriately. However, as most of this

\footnotetext{
* Correspondence: anca.sfaerlea@med.uni-muenchen.de

${ }^{\dagger}$ Anca Sfärlea and Sandra Dehning contributed equally to this work.

${ }^{1}$ Department of Child and Adolescent Psychiatry, Psychosomatics and Psychotherapy, University Hospital, LMU Munich, Pettenkoferstr. 8a, 80336 Munich, Germany

Full list of author information is available at the end of the article
}

research on alexithymia and emotion regulation has been conducted in adult samples, it is not known if the results can also be applied to adolescent patients. Furthermore, little is known about the relationship between alexithymia and emotion regulation. Therefore, our study assessed alexithymia and emotion regulation skills in three groups of adolescent girls: girls with anorexia nervosa, girls with major depression, and healthy girls. Both patient groups reported higher levels of alexithymia and made less use of adaptive emotion regulation strategies and more use of maladaptive emotion regulation strategies, compared to healthy girls. Alexithymia was associated with both adaptive emotion regulation

(c) The Author(s). 2019 Open Access This article is distributed under the terms of the Creative Commons Attribution 4.0 International License (http://creativecommons.org/licenses/by/4.0/), which permits unrestricted use, distribution, and reproduction in any medium, provided you give appropriate credit to the original author(s) and the source, provide a link to the Creative Commons license, and indicate if changes were made. The Creative Commons Public Domain Dedication waiver (http://creativecommons.org/publicdomain/zero/1.0/) applies to the data made available in this article, unless otherwise stated. 
strategies (negatively) and maladaptive emotion regulation strategies (positively), but explained additional variance only in maladaptive emotion regulation strategies, while the use of adaptive emotion regulation strategies was explained by depressive symptoms. Our results add to the small body of research on alexithymia and emotion regulation in adolescent psychiatric patients and suggest that different mechanisms may underlie the lack of adaptive and the surplus of maladaptive emotion regulation strategies in these patients.

\section{Background}

Among adolescent girls, anorexia nervosa (AN) and major depression (MD) are common mental health problems (e.g., $[1,2])$ that frequently occur comorbidly (e.g., $[3,4])$. For adolescents with AN and MD, regulating emotions in a healthy way seems to be difficult (e.g., $[5,6])$, but research in adolescent patients is limited [7, 8]. Emotion regulation difficulties can persist into adult age (e.g., $[9,10])$, can contribute to the maintenance of the disorders $[11,12]$ and seem to be not specific for certain mental disorders but rather a transdiagnostic characteristic (e.g., $[13,14])$.

Strategies to regulate emotions can be classified into adaptive (e.g., acceptance, problem-solving, reappraisal) and maladaptive strategies (e.g., rumination, avoidance, suppression) $[8,15]$. They usually develop from infancy to adulthood (e.g., $[16,17])$, with a so-called "maladaptive shift" occurring between 12 and 15 years $[17,18]$. At this age, the use of adaptive emotion regulation strategies decreases while the use of maladaptive strategies increases. This can be explained, i.a., by neuroendocrinological maturation [19-21] and the transition from parent-guided to self-guided emotion regulation [22]. This "maladaptive shift" is not specific for adolescents suffering from mental disorders but typically occurs in adolescents; however, it may explain why adolescence is a particularly vulnerable period for the development of mental disorders [23, 24].

A psychological construct related to emotion dysregulation is alexithymia, which literally means "no words for mood" and refers to difficulties in identifying and describing one's emotions (e.g., $[25,26]$ ). While numerous studies have linked alexithymia to various mental disorders including $A N$ and $M D$ in adults (see e.g., [26-28]), less is known about alexithymia in adolescent patients [29]: Alexithymia has been found to be increased in adolescents with AN (e.g., $[30,31])$ and to be related to depressive symptoms in adolescents [32] but has not been investigated in adolescents with MD [33]. However, alexithymia has been found to be associated with non-suicidal self-injury (e.g., [34, 35]) and to characterise adolescents with borderline personality disorder [36], indicating that it plays an essential role in disordered emotional functioning in adolescence.

Alexithymia has often been considered as a part of deficient emotion regulation (e.g., [25]) but it could be speculated that the ability to recognise one's own emotional reactions is actually a necessary premise for adaptive emotion regulation (e.g., [29, 37, 38]): individuals who struggle with detecting and naming their emotional state in a specific situation may find it particularly difficult to choose an appropriate strategy to regulate this emotional state as this requires understanding of the specific emotional elicitors as well as the elicited emotions [39]. This idea is in line with results from a study in adult inpatients with AN that found alexithymia at admission to predict emotion dysregulation at discharge [40], suggesting that alexithymia might interfere with therapeutic attempts to improve emotion regulation. Relationships between alexithymia and emotion regulation have also been reported in a mixed group of adolescent inpatients [29] as well as student samples $[39,41,42]$ but the exact mechanisms relating alexithymia to emotion regulation are not fully understood. Research in adolescent psychiatric patients is particularly scarce and, so far, no study has examined to what extent alexithymia predicts emotion regulation in adolescents separately for adaptive and maladaptive emotion regulation strategies. This seems important considering that different emotion regulation strategies have been found to be differently related to alexithymia in young adults [41].

Therefore, the present study was designed to investigate the role of alexithymia for emotion regulation in two groups of adolescent psychiatric patients: girls with $\mathrm{AN}$ and girls with MD, compared to healthy girls. First, we aimed to elucidate if alexithymia and emotion regulation skills differ between adolescent girls with AN or MD and healthy girls. Second, we wanted to determine whether alexithymia functions as a predictor for emotion regulation skills, over and above age and depressive symptoms, which are known to be related to emotion regulation (e.g., $[8,43])$. This would be in line with the notion that the ability to recognise one's own emotional reactions represents a premise for adaptive emotion regulation. In line with the literature (e.g., $[5,6,31,32])$, we expected adolescents with AN and MD to report higher alexithymia scores as well as to use less adaptive and more maladaptive emotion regulation strategies. Furthermore, as alexithymia has been found to be related to emotion regulation difficulties (e.g., [29, 42]), we expected alexithymia to be a negative predictor for adaptive emotion regulation strategies and a positive predictor for maladaptive emotions regulation strategies. 


\section{Methods}

\section{Participants}

The present data were collected within a study on emotional face processing in AN [44, 45]. The study sample consisted of 35 healthy girls, 26 girls with AN, and 25 girls with MD, aged 12 to 18 years. ${ }^{1}$ Girls with AN and MD were inpatients or outpatients from the Department of Child and Adolescent Psychiatry, Psychosomatics and Psychotherapy of the University Hospital Munich, Germany. Girls in the healthy control (HC) group were recruited through previous studies in which they had participated as HCs. Written information about the study together with an invitation to take part was sent to their families. Other $\mathrm{HC}$ girls were recruited through local advertisements. All interested $\mathrm{HC}$ participants were initially screened by asking their parents about any mental health problems of the adolescent before inviting them to our lab.

Psychiatric diagnoses were assessed in all participants using a standardised, semi-structured clinical interview (Kinder-DIPS [47]). The Kinder-DIPS is a well-established German diagnostic interview that allows diagnosis of a wide range of axis I disorders in children and adolescents and shows good inter-rater reliabilities for all diagnostic clusters [48]. The interviews were conducted and evaluated by trained interviewers with both, participants and their parents. Exclusion criteria for all participants were $\mathrm{IQ}<85$ (measured via the CFT-20-R [49]), current neurological disorders, pervasive developmental disorders, attention deficit and hyperactivity disorder, schizophrenic disorder, and bipolar disorder.

Girls were included in the $\mathrm{HC}$ group if they did not meet criteria for any current or past axis I disorder as assessed via the Kinder-DIPS.

Girls were included in the AN group if they met criteria for AN according to ICD-10 (F50.0 [50]) and had a body mass index (BMI) on or below the 3rd age-corrected percentile according to KiGGS [51]. Sixteen of the included AN patients fulfilled criteria for at least one comorbid condition, including $\mathrm{MD}$, conduct disorder, and anxiety disorders. Depression was the most frequent comorbid diagnosis $(n=13)$ and had developed secondary to the eating disorder in most cases. ${ }^{2}$

\footnotetext{
${ }^{1}$ Only girls who completed all questionnaires were included. One girl was identified as outlier in the regression analysis (according to [46]) and thus excluded from all analyses.

${ }^{2}$ Participants with comorbid MD were not excluded as this would have led to a non-representative sample given the high comorbidity between AN and MD (e.g., [3]) and AN patients not meeting criteria for MD also showing substantially elevated depressive symptoms.
}

Girls were included in the MD group if they currently met criteria for an episode of MD (F32 or F33 in the ICD-10 [50]) and did not report any symptoms of an eating disorder. Within the MD group, 10 patients met criteria for one or more comorbid anxiety disorders.

\section{Measures}

Depressive symptoms were assessed with the German version of the Beck Depression Inventory-II (BDI-II [52]), a 21-item self-report questionnaire that allows valid assessment of depressive symptoms in adolescents [53]. Internal consistency in our sample was excellent (Cronbach's $\alpha=.95$ ).

To measure alexithymia, the German version of the Toronto Alexithymia Scale (TAS [54]) was used. The TAS is a self-report questionnaire for the valid assessment of three dimensions of alexithymia: (1) difficulty identifying feelings, (2) difficulty describing feelings, and (3) externally oriented thinking. Eighteen items were rated on a five-point scale and summed up to a total alexithymia score. Internal consistency in our sample was good (Cronbach's $\alpha=.83)$.

The German questionnaire on emotion regulation in children and adolescents (FEEL-KJ [55]) was administered to measure emotion regulation skills. The 90-item self-report questionnaire assesses the habitual use of adaptive (acceptance, cognitive problem solving, distraction, forgetting, humour enhancement, problem-oriented action, reevaluation) and maladaptive strategies (aggressive behavior, giving up, rumination, self-devaluation, withdrawal) to regulate anxiety, fear, and sadness in children and adolescents and has proven to be valid and reliable [56]. Each item (e.g., "I try to change what makes me angry", "I cannot get it out of my head") is rated on a five-point scale according to how often this strategy is applied to regulate each of the emotions. Sum scores for adaptive and maladaptive strategies across all emotions were calculated. Internal consistencies in our sample were good (Cronbach's $\alpha \mathrm{s} \geq .89$ ).

\section{Data analysis}

Statistical analyses were conducted with SPSS 24. To assess group differences one-way analyses of variance (ANOVAs) and follow-up $t$-tests were conducted. Hierarchical linear regressions were used to determine the extent to which variations in alexithymia explain variations in emotion regulation in addition to known predictors: In a first step, age and depressive symptoms were included as predictors; in a second step alexithymia was 
added. Outcome variables were adaptive as well as maladaptive emotion regulation strategies. The significance level ( $p=.05$, two-tailed) was adjusted according to the Bonferroni-Holm procedure [57] when performing multiple post-hoc comparisons.

\section{Results}

\section{Group comparisons}

Characteristics of the three groups are presented in Table 1. The groups were comparable in terms of age and IQ but differed, as expected, regarding BMI (with the AN group having a lower BMI and age-corrected BMI-percentile than the MD and HC groups; $t \mathrm{~s} \geq 6.0$, $p \mathrm{~s}<.001, d \mathrm{~s} \geq 1.7$ ) and depressive symptoms (with both patient groups reporting more depressive symptoms than the HC group: $t \mathrm{~s} \geq 8.4, p \mathrm{~s}<.001, d \mathrm{~s} \geq 2.4$; while not differing from each other: $\left.t_{49}=1.1, p>.1\right)$. Both patient groups reported more pronounced alexithymia than the HC group ( $t \mathrm{~s} \geq 7.3, p \mathrm{~s}<.001, d \mathrm{~s} \geq 2.0$ ), but did not differ from each other $(t<1)$. AN and MD groups reported to use adaptive emotion regulation strategies less frequently $(t \mathrm{~s} \geq 2.8, \quad p \mathrm{~s} \leq .008, d \mathrm{~s} \geq 0.7)$ and maladaptive emotion regulation strategies more frequently $(t \mathrm{~s} \geq 5.8, p \mathrm{~s}<.001$, $d s \geq 1.0)$ than the $\mathrm{HC}$ group, while not differing from each other $(t s \leq 1.6, p s>.05)$. Emotion regulation strategies and alexithymia were highly correlated with each other as well as with depressive symptoms, but not related to age (Table 2).

\section{Prediction of emotion regulation strategies}

The hierarchical regression revealed that age and depressive symptoms accounted for a significant proportion of variance of adaptive emotion regulation strategies $\left(F_{2,83}=9.9, p<.001, R^{2}=.19\right)$. Adding alexithymia to the model did not increase the proportion of explained variance significantly $(p>.1)$. Depressive
Table 2 Pearson-Correlations

\begin{tabular}{|c|c|c|c|c|}
\hline & Age & $\begin{array}{l}\text { Depressive } \\
\text { symptoms }\end{array}$ & Alexithymia & $\begin{array}{l}\text { Adaptive } \\
\text { emotion } \\
\text { regulation } \\
\text { strategies }\end{array}$ \\
\hline Depressive symptoms & -.14 & & & \\
\hline Alexithymia & .00 & $.80^{*}$ & & \\
\hline $\begin{array}{l}\text { Adaptive emotion regulation } \\
\text { strategies }\end{array}$ & .14 & $-.43^{*}$ & $-.37^{*}$ & \\
\hline $\begin{array}{l}\text { Maladaptive emotion regulation } \\
\text { strategies }\end{array}$ & .03 & $.58^{*}$ & $.66^{*}$ & $-.42^{*}$ \\
\hline
\end{tabular}

symptoms were a significant negative predictor for adaptive emotion regulation strategies, while age and alexithymia were not (Table 3 ).

For maladaptive emotion regulation strategies, the analysis revealed that age and depressive symptoms accounted for a significant proportion of variance $\left(F_{2,83}=21.9, p<.001\right.$, $R^{2}=.35$ ). Adding alexithymia to the model increased the explained variance significantly $\left(\Delta R^{2}=.10, p<.001\right)$ resulting on a total of $44 \%$ of variance explained $\left(F_{3,82}=21.6, p<.001\right.$, $\left.R^{2}=.44\right)$. Alexithymia was a significant positive predictor for maladaptive emotion regulation strategies in the final model, while age and depressive symptoms were not (Table 3).

In both regression analyses tolerance values were $>.2$, indicating that multicollinearity was not a problem [46].

\section{Discussion}

The present study investigated alexithymia and emotion regulation in adolescent girls with $\mathrm{AN}$ or MD and healthy girls. Both patient groups reported higher alexithymia scores as well as less adaptive and more maladaptive emotion regulation strategies than HCs. Alexithymia was a strong positive predictor for maladaptive emotion regulation strategies while adaptive emotion regulation strategies were negatively predicted by depressive symptoms.

Table 1 Demographic and clinical characteristics as well as emotional skills of the study sample

\begin{tabular}{|c|c|c|c|c|c|c|c|}
\hline & \multirow{3}{*}{$\begin{array}{c}H C \\
n=35 \\
M \\
(S D)\end{array}$} & \multirow{3}{*}{$\begin{array}{c}\text { AN } \\
n=26 \\
M \\
(S D)\end{array}$} & \multirow{3}{*}{$\begin{array}{c}M D \\
n=25 \\
M \\
(S D)\end{array}$} & \multicolumn{3}{|c|}{ ANOVA } & \multirow[t]{3}{*}{ post-hoc tests } \\
\hline & & & & \multirow[b]{2}{*}{$F_{2,83}$} & \multirow[b]{2}{*}{$p$} & \multirow[b]{2}{*}{$\eta_{p}^{2}$} & \\
\hline & & & & & & & \\
\hline Age & $15.2(1.8)$ & $15.2(1.7)$ & $14.7(1.6)$ & 1.0 & n.s. & .03 & \\
\hline IQ & $105.9(10.3)$ & $106.6(15.0)$ & $110.9(12.5)$ & 1.2 & n.s. & .03 & \\
\hline BMl & $19.8(2.0)$ & $15.4(1.2)$ & $21.4(4.9)$ & 28.0 & $<.001$ & .40 & $\mathrm{AN}<\mathrm{HC}=\mathrm{MD}$ \\
\hline BMI-percentile (age-corrected) & $36.0(22.0)$ & $0.8(1.2)$ & $49.2(32.4)$ & 32.5 & $<.001$ & .44 & $\mathrm{AN}<\mathrm{HC}=\mathrm{MD}$ \\
\hline Depressive symptoms & $4.4(3.8)$ & $23.8(9.7)$ & $27.3(13.2)$ & 55.9 & $<.001$ & .57 & $\mathrm{HC}<\mathrm{AN}=\mathrm{MD}$ \\
\hline Alexithymia & $40.4(6.2)$ & $54.7(8.1)$ & $57.1(8.3)$ & 45.1 & $<.001$ & .52 & $\mathrm{HC}<\mathrm{AN}=\mathrm{MD}$ \\
\hline \multicolumn{8}{|l|}{ Emotion regulation strategies } \\
\hline Adaptive strategies & $131.6(25.9)$ & $111.8(30.0)$ & $104.4(25.6)$ & 8.2 & .001 & .16 & $\mathrm{HC}>\mathrm{AN}=\mathrm{MD}$ \\
\hline Maladaptive strategies & 76.5 (15.7) & $92.4(15.0)$ & $99.2(13.8)$ & 18.4 & $<.001$ & .31 & $\mathrm{HC}<\mathrm{AN}=\mathrm{MD}$ \\
\hline
\end{tabular}

HC Healthy controls, AN Anorexia nervosa, MD Major depression, IQ Intelligence quotient, BMI Body mass index, $M$ Mean, SD Standard deviation; posthoc $t$-tests were all significant with $p<.01$ 
Table 3 Results of the regression analyses predicting emotion regulation strategies as a function of age, depression, and alexithymia

\begin{tabular}{|c|c|c|c|c|c|c|}
\hline & B & SE for $B$ & $95 \% C l$ for $B$ & $\beta$ & $t$ & $p$ \\
\hline \multicolumn{7}{|l|}{ Adaptive strategies } \\
\hline \multicolumn{7}{|l|}{ STEP 1: } \\
\hline Age & 1.4 & 1.7 & {$[-2.0,4.8]$} & .08 & $<1$ & n.s. \\
\hline Depressive symptoms & -0.9 & 0.2 & {$[-1.3,-0.5]$} & -.42 & -4.2 & $<.001$ \\
\hline \multicolumn{7}{|l|}{ STEP 2: } \\
\hline Age & 1.6 & 1.8 & {$[-1.9,5.1]$} & .09 & $<1$ & n.s. \\
\hline Depressive symptoms & -0.7 & 0.4 & {$[-1.5,-0.0]$} & -.35 & -2.1 & .043 \\
\hline Alexithymia & -0.2 & 0.5 & {$[-1.2,0.7]$} & -.08 & $<1$ & n.s. \\
\hline \multicolumn{7}{|l|}{ Maladaptive strategies } \\
\hline \multicolumn{7}{|l|}{ STEP 1: } \\
\hline Age & 1.1 & 0.9 & {$[-0.7,3.0]$} & .11 & 1.2 & .230 \\
\hline Depressive symptoms & 0.8 & 0.1 & {$[0.5,1.0]$} & .59 & 6.6 & $<.001$ \\
\hline \multicolumn{7}{|l|}{ STEP 2: } \\
\hline Age & 0.5 & 0.9 & {$[-1.3,2.3]$} & .05 & $<1$ & n.s. \\
\hline Depressive symptoms & 0.2 & 0.2 & {$[-0.2,0.6]$} & .16 & 1.2 & .253 \\
\hline Alexithymia & 0.9 & 0.2 & {$[0.4,1.3]$} & .53 & 3.8 & $<.001$ \\
\hline
\end{tabular}

In line with our expectations, we found that girls with $\mathrm{AN}$ as well as girls with MD displayed higher alexithymia scores and reported using adaptive emotion regulation strategies less frequently and maladaptive emotion regulation strategies more frequently compared to HCs. This is consistent with prior studies in adolescents (e.g., [5, 6, 30$32,58-60])$ and adds to the small body of literature on alexithymia and emotion regulation in adolescent psychiatric patients. The two patient groups did not differ from each other, suggesting that both, difficulties in recognising and verbalising as well as regulating one's emotions do not characterise AN or MD specifically but might represent transdiagnostic factors already in adolescence, which is in line with prior studies on alexithymia [29] and emotion regulation [61] in children and adolescents with different mental disorders. However, different diagnostic groups might differ with respect to the specific emotion regulation strategies, ${ }^{3}$ so future studies should investigate different adaptive and maladaptive emotion regulation strategies separately in larger samples of adolescents with $\mathrm{AN}$ and $\mathrm{MD}$, as this will allow a more differentiated understanding of emotion regulation difficulties in these groups.

The regression analyses showed that alexithymia was a significant positive predictor for maladaptive regulation strategies, but adaptive emotion regulation strategies were

\footnotetext{
${ }^{3}$ Explorative analyses of our data indicated that there might be differences for specific emotion regulation strategies between AN and MD patients, particularly for the maladaptive strategy giving up which seemed to be employed more often by MD patients than by AN patients. However, our restricted sample size does not allow confident interpretation of these analyses, so the investigation of different emotion regulation strategies separately remains subject to future research.
}

negatively predicted only by depressive symptoms. This is in line with studies in healthy adults that found alexithymia to be related to the maladaptive emotion regulation strategy suppression, but not the adaptive strategy reappraisal ([41, 62, 63]; but see also [42]). Alexithymia being a strong predictor for maladaptive emotion regulation strategies suggests that uncertainty about one's emotions enhances the use of inadequate strategies to regulate them. Venta et al. [29] suggested that this relation might be explained by experiential avoidance: On the one hand, avoidance of aversive experiences may interfere with learning how to use emotional language in a pragmatic way, thereby contributing to alexithymia, on the other hand, it may prevent individuals to learn how to deal with difficult situations, leading to reduced emotion regulation abilities. Alternatively, one could suspect that the difficulties in perceiving and verbalising one's feelings might impede individuals' ability to reflect upon their feelings and to generate emotion-specific, appropriate reactions, thereby fostering maladaptive behaviour like aggression or withdrawal [39].

The result that depressive symptoms were a negative predictor for adaptive emotion regulation strategies on the other hand, might be accounted for by different explanations. One is the decrease of positive activity, which is one of the core symptoms of depressive disorders [50] and might involve reduced availability of adaptive strategies as distraction or humour enhancement. Another possible explanation are cognitive biases for negative information that are associated with depression $[64,65]$ and presumably render revaluation of emotion-eliciting situations difficult. However, both explanations are highly speculative and the relationship between emotion regulation and depressive symptoms is likely of bidirectional nature, as difficulties in emotion regulation are 
both, a risk factor for depression (e.g., [66]) as well as a result of depressive symptomatology (the latter seems to apply particularly to the adaptive strategy reappraisal [67]).

Of note, in the first step of the regression, depressive symptoms predicted the use of both adaptive as well as maladaptive emotion regulation strategies, as expected (e.g., [8]). However, entering alexithymia into the regression model reduced the influence of depressive symptoms. This presumably results from the high correlation between depressive symptoms and alexithymia in our sample (which is in line with e.g., [58, 68]). It is arguable if alexithymia can be assessed validly in depressed samples (e.g., [69]), as it is still unknown whether alexithymia is a state that depends on depressive symptoms and decreases as these remit (e.g., [70]) or rather a stable personality trait (e.g., [71]). Our results show that in spite of sharing a great amount of variance, depressive symptoms and alexithymia have differential influence on adaptive and maladaptive emotion regulation strategies in adolescents, suggesting that different mechanisms may underlie the lack of adaptive and the surplus of maladaptive emotion regulation strategies in adolescent psychiatric patients. As the present study was the first to investigate the interplay between alexithymia and emotion regulation in adolescent girls with $\mathrm{AN}$ and $\mathrm{MD}$, further studies that also include weight-restored or remitted patients are necessary to further disentangle the differential influence of depressive symptoms and alexithymia on emotion regulation. For example, if the use of adaptive strategies depends mainly on depressive symptoms and the use of maladaptive strategies depends more on alexithymia, one could suspect that the lack of adaptive strategies improves with remission of depressive symptoms while the use of maladaptive strategies might remain - at least to some extent - increased, unless a decrease in alexithymia occurs.

An important limitation of our study results from our AN and MD samples reporting a comparable amount of depressive symptoms. ${ }^{4}$ Considering the close connection between depressive symptoms and alexithymia, this might have masked differences in alexithymia between these groups (depressive symptoms have been found to explain alexithymia in AN partially but not entirely [68]). It might also have prevented us from finding differences in emotion regulation like Brockmeyer et al. [9] reported between adults with AN (without comorbid depression) and MD (with both patient groups showing greater emotion regulation difficulties than $\mathrm{HCs}$ but MD patients reporting even greater difficulties than AN patients). In addition, a considerable proportion of patients in both groups had comorbid anxiety disorders. Therefore, we cannot draw conclusions that are specific for girls with AN or MD from the group comparisons.

\footnotetext{
${ }^{4}$ Of note, some of the depressive symptoms in AN patients may be accounted for by malnutrition (e.g., [72]).
}

Another limitation is the size and composition of the study sample. As mentioned above, the limited sample size prevented us from investigating group differences in different emotion regulation strategies. The heterogenity of the patient groups, which comprised in- a well as outpatients with different disorder severities and comorbid conditions, might have further contributed to the inability to detect differences between AN and MD patients.

The interpretation of our results is also limited by the fact that our study relies solely on self-report measures. Adolescents' self-reported emotion regulation strategies might not reflect the actual behaviour when encountering negative emotions [73] and reporting to use adaptive emotion regulation strategies less frequently may not necessarily implicate less successful emotion regulation (e.g., [74]). Future studies should investigate both, selfreported emotion regulation skills and performance in emotion regulation tasks to elucidate if adolescent AN and MD patients indeed are less successful in regulating their emotions or if they underestimate their actual abilities.

Importantly, due to the cross-sectional design of the study, we cannot draw conclusions regarding causality and temporal relationships: it is possible that the inability to identify one's emotions (i.e., being alexithymic) indeed precedes and is a cause of maladaptive emotion regulation but it is also possible that another factor influences both, difficulties in emotion regulation and alexithymia. Longitudinal studies could shed light on these possibilities as well as the aforementioned question of stability of the relationship between alexithymia and emotion regulation in remission.

Our study has important clinical implications. Our result of alexithymia explaining a substantial part of variance in maladaptive emotion regulation, together with the finding that alexithymia has a negative impact on treatment outcome (e.g., [75, 76]), presumably, i.a., by interfering with therapeutic attempts to improve emotion regulation [40], stresses the importance of addressing adolescent patients' abilities to identify and express their emotions in order to improve their emotion regulation abilities. Given that improving emotion regulation has been found to improve treatment outcomes in patients with AN and MD (e.g., [11, 12, 77]) and considering that development of functional emotion regulation skills is an essential task in adolescence (e.g., [23]), young patients may especially benefit from therapies focused on their emotional competencies.

\section{Conclusion}

Our study was the first to investigate the interplay between alexithymia, depressive symptoms, and adaptive as well as maladaptive emotion regulation strategies in adolescent girls with AN and MD in comparison to healthy 
girls. The results replicate findings of more pronounced alexithymia as well as less adaptive and more maladaptive emotion regulation strategy use in the patient groups. Furthermore, they suggest that alexithymia and depressive symptoms have differential influence on adaptive and maladaptive emotion regulation strategies, partially supporting the idea that the ability to recognise and describe one's own emotions might be a necessary premise for successful emotion regulation. However, additional studies are needed to elucidate this topic and other explanations should also be considered.

\section{Abbreviations}

AN: Anorexia nervosa; ANOVA: Analysis of variance; BDI-II: Beck Depression Inventory-II; BMI: Body mass index; FEEL-KJ: Fragebogen zur Erhebung der Emotionsregulation bei Kindern und Jugendlichen [questionnaire on emotion regulation in children and adolescents]; HC: Healthy control; IQ: Intelligence quotient; Kinder-DIPS: Diagnostisches Interview bei psychischen Störungen im Kindes- und Jugendalter [diagnostic interview for mental disorders in childhood and adolescence]; MD: Major depression; TAS: Toronto Alexithymia Scale

\section{Acknowledgements}

We would like to thank all participants and their families for taking part in this study and our study nurse team for their help in participant recruitment and data collection.

\section{Authors' contributions}

AS collected and analyzed the data. AS, SD, and LKK interpreted the data and wrote the manuscript. GSK supervised all steps and contributed to writing the manuscript. All authors read and approved the final manuscript.

\section{Funding}

The present study was supported by the "Förderprogramm für Forschung und Lehre" (FöFoLe; Reg.-Nr. 800/788) of the Medical Faculty of the LMU Munich. The funder played no role in study design, data collection, analysis and interpretation of the data, or preparation of the manuscript.

\section{Availability of data and materials}

The datasets generated and analysed during the current study are not publicly available because no consent for making the data publicly available was collected from the participants. However, the data are available from the corresponding author on reasonable request.

\section{Ethics approval and consent to participate}

The study was approved by the ethics committee of the Medical Faculty of the LMU Munich (Project 482-12) and all procedures were in accordance with the latest version of the Declaration of Helsinki. Prior to participation, written informed consent was obtained from all participants and their parents/legal guardians after a comprehensive explanation of the study procedures.

\section{Consent for publication}

Not applicable.

\section{Competing interests}

The authors declare that they have no competing interests.

\section{Author details}

'Department of Child and Adolescent Psychiatry, Psychosomatics and Psychotherapy, University Hospital, LMU Munich, Pettenkoferstr. 8a, 80336 Munich, Germany. ${ }^{2}$ Faculty of Medicine, Institute of Medical Psychology, LMU, Munich, Germany.
Received: 9 July 2019 Accepted: 30 October 2019

Published online: 29 November 2019

\section{References}

1. Smink FR, van Hoeken D, Hoek HW. Epidemiology of eating disorders: incidence, prevalence and mortality rates. Curr Psychiatry Rep. 2012;14:40614. https://doi.org/10.1007/s11920-012-0282-y.

2. Wartberg L, Kriston L, Thomasius R. Depressive symptoms in adolescents: prevalence and associated psychosocial features in a representative sample. Dtsch Arztebl Int. 2018;115:549-55. https://doi.org/10.3238/arztebl.2018.0549.

3. Jaite C, Hoffmann F, Glaeske G, Bachmann CJ. Prevalence, comorbidities and outpatient treatment of anorexia and bulimia nervosa in German children and adolescents. Eat Weight Disord. 2013;18:157-65. https://doi.org/10.1007/ s40519-013-0020-4.

4. Lewinsohn PM, Hops H, Roberts RE, Seeley JR, Andrews JA. Adolescent psychopathology: I. prevalence and incidence of depression and other DSM-III-R disorders in high school students. J Abnorm Psychol. 1993;102: 133-44. https://doi.org/10.1037/0021-843X.102.1.133.

5. Brytek-Matera A. Anorexia nervosa among French adolescent females in relation to self-esteem, coping strategies, anger expression and anger control. Arch Psychiatry Psychother. 2007:4:53-7.

6. Kullik A, Petermann F. Dysfunctional emotion regulation as a basic factor of anxiety and depressive disorders in adolescents. Fortschr Neurol Psychiatr. 2013:81:35-9. https://doi.org/10.1055/s-0032-1330320.

7. Lavender JM, Wonderlich SA, Engel SG, Gordon KH, Kaye WH, Mitchell JE. Dimensions of emotion dysregulation in anorexia nervosa and bulimia nervosa: a conceptual review of the empirical literature. Clin Psychol Rev. 2015;40:111-22. https://doi.org/10.1016/j.cpr.2015.05.010.

8. Schäfer JÖ, Naumann E, Holmes EA, Tuschen-Caffier B, Samson AC. Emotion regulation strategies in depressive and anxiety symptoms in youth: a metaanalytic review. J Youth Adolesc. 2017;46:261-76. https://doi.org/10.1007/ s10964-016-0585-0.

9. Brockmeyer T, Bents H, Holtforth MG, Pfeiffer N, Herzog W, Friederich HC. Specific emotion regulation impairments in major depression and anorexia nervosa. Psychiatry Res. 2012;200:550-3. https://doi.org/10.1016/j.psychres. 2012.07.009

10. Donofry SD, Roecklein KA, Wildes JE, Miller MA, Erickson KI. Alterations in emotion generation and regulation neurocircuitry in depression and eating disorders: a comparative review of structural and functional neuroimaging studies. Neurosci Biobehav Rev. 2016;68:911-27. https://doi.org/10.1016/j. neubiorev.2016.07.011.

11. Racine SE, Wildes JE. Dynamic longitudinal relations between emotion regulation difficulties and anorexia nervosa symptoms over the year following intensive treatment. J Consult Clin Psychol. 2015:83:785-95. https://doi.org/10.1037/ccp0000011.

12. Arditte KA, Joormann J. Emotion regulation in depression: reflection predicts recovery from a major depressive episode. Cognit Ther Res. 2011; 35:536-43. https://doi.org/10.1007/s10608-011-9389-4.

13. Svaldi J, Griepenstroh J, Tuschen-Caffier B, Ehring T. Emotion regulation deficits in eating disorders: a marker of eating pathology or general psychopathology? Psychiatry Res. 2012;197:103-11. https://doi.org/10.1016/j. psychres.2011.11.009.

14. Aldao A, Nolen-Hoeksema S. Specificity of cognitive emotion regulation strategies: a transdiagnostic examination. Behav Res Ther. 2010;48:974-83. https://doi.org/10.1016/j.brat.2010.06.002.

15. Aldao A, Nolen-Hoeksema S, Schweizer S. Emotion-regulation strategies across psychopathology: a meta-analytic review. Clin Psychol Rev. 2010;30: 217-37. https://doi.org/10.1016/j.cpr.2009.11.004.

16. Zeman J, Cassano M, Perry-Parrish C, Stegall S. Emotion regulation in children and adolescents. J Dev Behav Pediatr. 2006;27:155-68. https://doi. org/10.1097/00004703-200604000-00014.

17. Zimmermann P, Iwanski A. Emotion regulation from early adolescence to emerging adulthood and middle adulthood: age differences, gender differences, and emotion-specific developmental variations. Int J Behav Dev. 2014;38:182-94. https://doi.org/10.1177/0165025413515405.

18. Cracco E, Goossens L, Braet C. Emotion regulation across childhood and adolescence: evidence for a maladaptive shift in adolescence. Eur Child Adolesc Psychiatry. 2017;26:909-21. https://doi.org/10.1007/s00787-017-0952-8.

19. Ahmed SP, Bittencourt-Hewitt A, Sebastian CL. Neurocognitive bases of emotion regulation development in adolescence. Dev Cogn Neurosci. 2015; 15:11-25. https://doi.org/10.1016/j.dcn.2015.07.006 
20. Sisk $C L$, Zehr JL. Pubertal hormones organize the adolescent brain and behavior. Front Neuroendocrinol. 2005;26:163-74. https://doi.org/10.1016/j. yfrne.2005.10.003.

21. Somerville LH, Jones RM, Casey B. A time of change: behavioral and neural correlates of adolescent sensitivity to appetitive and aversive environmental cues. Brain Cogn. 2010;72:124-33. https://doi.org/10.1016/j.bandc.2009.07. 003.

22. Thompson RA, Goodman M. Development of emotion regulation: more than meets the eye. In: Kring AM, Sloan DM, editors. Emotion regulation and psychopathology: a Transdiagnostic approach to etiology and treatment. New York: Guilford Press; 2010. p. 38-58.

23. McLaughlin KA, Hatzenbuehler ML, Mennin DS, Nolen-Hoeksema S. Emotion dysregulation and adolescent psychopathology: a prospective study. Behav Res Ther. 2011;49:544-54. https://doi.org/10.1016/j.brat.2011.06.003.

24. Nolen-Hoeksema S, Stice E, Wade E, Bohon C. Reciprocal relations between rumination and bulimic, substance abuse, and depressive symptoms in female adolescents. J Abnorm Psychol. 2007;116:198. https://doi.org/10. 1037/0021-843X.116.1.198.

25. Taylor GJ. Recent developments in alexithymia theory and research. Can J Psychiatr. 2000;45:134-42. https://doi.org/10.1177/070674370004500203.

26. Westwood H, Kerr-Gaffney J, Stahl D, Tchanturia K. Alexithymia in eating disorders: systematic review and meta-analyses of studies using the Toronto alexithymia scale. J Psychosom Res. 2017;99:66-81. https://doi.org/10.1016/j. jpsychores.2017.06.007.

27. Nowakowski ME, McFarlane T, Cassin S. Alexithymia and eating disorders: a critical review of the literature. J Eat Disord. 2013;1:1-14. https://doi.org/10. 1186/2050-2974-1-21.

28. Li S, Zhang B, Guo Y, Zhang J. The association between alexithymia as assessed by the 20-item Toronto alexithymia scale and depression: a meta-analysis. Psychiatry Res. 2015;227:1-9. https://doi.org/10.1016/j.psychres.2015.02.006.

29. Venta A, Hart J, Sharp C. The relation between experiential avoidance, alexithymia and emotion regulation in inpatient adolescents. Clin Child Psychol Psychiatry. 2013;18:398-410. https://doi.org/10.1177/ 1359104512455815

30. Lulé D, Schulze UM, Bauer K, Schöll F, Müller S, Fladung A-K, Uttner I. Anorexia nervosa and its relation to depression, anxiety, alexithymia and emotional processing deficits. Eat Weight Disord. 2014;19:209-16. https:// doi.org/10.1007/s40519-014-0101-z

31. Zonnevylle-Bender MJS, van Goozen SHM, Cohen-Kettenis PT, van Elburg A, van Engeland $\mathrm{H}$. Emotional functioning in adolescent anorexia nervosa patients. Eur Child Adolesc Psychiatry. 2004;13:28-34. https://doi.org/10. 1007/s00787-004-0351-9.

32. Honkalampi K, Tolmunen T, Hintikka J, Rissanen M-L, Kylmä J, Laukkanen E. The prevalence of alexithymia and its relationship with youth self-report problem scales among Finnish adolescents. Compr Psychiatry. 2009;50:2638. https://doi.org/10.1016/j.comppsych.2008.08.007

33. Sendzik L, Schäfer JÖ, Samson AC, Naumann E, Tuschen-Caffier B. Emotional awareness in depressive and anxiety symptoms in youth: a meta-analytic review. J Youth Adolesc. 2017:46:687-700. https://doi.org/10.1007/s10964017-0629-0

34. Cerutti R, Zuffianò A, Spensieri V. The role of difficulty in identifying and describing feelings in non-suicidal self-injury behavior (NSSI): associations with perceived attachment quality, stressful life events, and suicidal ideation. Front Psychol. 2018:9:318. https://doi.org/10.3389/fpsyg. 2018.00318.

35. Lüdtke J, In-Albon T, Michel C, Schmid M. Predictors for DSM-5 nonsuicidal self-injury in female adolescent inpatients: the role of childhood maltreatment, alexithymia, and dissociation. Psychiatry Res. 2016;239:346-52. https://doi.org/10.1016/j.psychres.2016.02.026.

36. Loas G, Speranza M, Pham-Scottez A, Perez-Diaz F, Corcos M. Alexithymia in adolescents with borderline personality disorder. J Psychosom Res. 2012;72: 147-52. https://doi.org/10.1016/j.jpsychores.2011.11.006.

37. Feldman Barrett L, Gross J, Christensen TC, Benvenuto M. Knowing what you're feeling and knowing what to do about it: mapping the relation between emotion differentiation and emotion regulation. Cognit Emot. 2001;15:713-24. https://doi.org/10.1080/ 02699930143000239

38. Kranzler A, Young JF, Hankin BL, Abela JR, Elias MJ, Selby EA. Emotional awareness: a transdiagnostic risk factor for internalizing symptoms in children and adolescents? J Clin Child Adolesc Psychol. 2016:45:262-9. https://doi.org/10.1080/15374416.2014.987379.
39. Eastabrook JM, Flynn JJ, Hollenstein T. Internalizing symptoms in female adolescents: associations with emotional awareness and emotion regulation. J Child Fam Stud. 2014;23:487-96. https://doi.org/10.1007/ s10826-012-9705-y.

40. Brown TA, Avery JC, Jones MD, Anderson LK, Wierenga CE, Kaye W. The impact of alexithymia on emotion dysregulation in anorexia nervosa and bulimia nervosa over time. Eur Eat Disord Rev. 2018;26:150-5. https://doi. org/10.1002/erv.2574.

41. Laloyaux J, Fantini C, Lemaire M, Luminet O, Laroi F. Evidence of contrasting patterns for suppression and reappraisal emotion regulation strategies in alexithymia. J Nerv Ment Dis. 2015;203:709-17. https://doi.org/10.1097/nmd. 0000000000000353.

42. Swart M, Kortekaas $R$, Aleman A. Dealing with feelings: Characterization of trait alexithymia on emotion regulation strategies and cognitive-emotional processing. PLoS One. 2009;4:e5751. https://doi.org/10.1371/journal.pone.0005751.

43. Gullone E, Hughes EK, King NJ, Tonge B. The normative development of emotion regulation strategy use in children and adolescents: a 2-year follow-up study. J Child Psychol Psychiatry. 2010;51:567-74. https://doi.org/ 10.1111/j.1469-7610.2009.02183.x

44. Sfärlea A, Greimel E, Platt B, Bartling J, Schulte-Körne G, Dieler AC. Alterations in neural processing of emotional faces in adolescent anorexia nervosa patients - an event-related potential study. Biol Psychol. 2016;119: 141-55. https://doi.org/10.1016/j.biopsycho.2016.06.006.

45. Sfärlea A, Greimel E, Platt B, Dieler AC, Schulte-Körne G. Recognition of emotional facial expressions in adolescents with anorexia nervosa and adolescents with major depression. Psychiatry Res. 2018;262:586-94. https:// doi.org/10.1016/j.psychres.2017.09.048.

46. Field A. Discovering statistics using IBM SPSS statistics. 4th ed. London: Sage; 2013

47. Schneider S, Unnewehr S, Margraf J. Kinder-DIPS: Diagnostisches Interview bei psychischen Störungen im Kindes-und Jugendalter. 2nd ed. Heidelberg: Springer; 2009.

48. Neuschwander M, In-Albon T, Adornetto C, Roth B, Schneider S. InterraterReliabilität des Diagnostischen Interviews bei psychischen Störungen im Kindes- und Jugendalter (Kinder-DIPS) [Interrater reliability of the «Diagnostisches Interview bei psychischen Störungen im Kindes- und Jugendalter» (Kinder-DIPS)]. Z Kinder Jugendpsychiatr Psychother. 2013;41: 319-34. https://doi.org/10.1024/1422-4917//a000247.

49. Weiß RH. CFT 20-R. Grundintelligenztest Skala 2. Revision. Göttingen: Hogrefe; 2006.

50. Weltgesundheitsorganisation/World Health Organization. In: Dilling H, Mombour W, Schmidt MH, Schulte-Markwort E, editors, Internationale Klassifikation psychischer Störungen. ICD-10 Kapitel V(F). Diagnostische Kriterien für Forschung und Praxis. 4th ed. Bern: Hans Huber; 2008.

51. Neuhauser H, Schienkiewitz A, Schaffrath Rosario A, Dortschy R, Kurth B-M. Referenzperzentile für anthropometrische Maßzahlen und Blutdruck aus der Studie zur Gesundheit von Kindern und Jugendlichen in Deutschland (KiGGS) 2003-2006. Berlin: Robert-Koch-Institut; 2011

52. Hautzinger M, Keller F, Kühner C. BDI-II. Beck Depression-Inventar. Revision. Pearson: Frankfurt am Main; 2006.

53. Dolle K, Schulte-Körne G, O'Leary AM, von Hofacker N, Izat Y, Allgaier A-K. The Beck depression inventory-II in adolescent mental health patients: cutoff scores for detecting depression and rating severity. Psychiatry Res. 2012; 200:843-8. https://doi.org/10.1016/j.psychres.2012.05.011.

54. Kupfer J, Brosig B, Brähler E. Toronto-Alexithymie-Skala-26 (TAS-26). Göttingen: Hogrefe; 2001.

55. Grob A, Smolenski C. FEEL-KJ. Fragebogen zur Erhebung der Emotionsregulation bei Kindern und Jugendlichen. 2nd ed. Bern: Hans Huber; 2009.

56. Cracco E, Van Durme $K$, Braet C. Validation of the FEEL-KJ: an instrument to measure emotion regulation strategies in children and adolescents. PLoS One. 2015;10:e0137080. https://doi.org/10.1371/journal.pone.0137080.

57. Holm S. A simple sequentially rejective multiple test procedure. Scand J Stat. 1979:6:65-70

58. Peres V, Corcos M, Robin M, Pham-Scottez A. Emotional intelligence, empathy and alexithymia in anorexia nervosa during adolescence. Eat Weight Disord. 2018. https://doi.org/10.1007/s40519-018-0482-5.

59. Rothschild-Yakar L, Peled M, Enoch-Levy A, Gur E, Stein D. "Eating me up from inside": a pilot study of mentalization of self and others and emotion regulation strategies among young women with eating disorders. Isr J Psychiatry Relat Sci. 2018;55:35-43. 
60. Hughes EK, Gullone E, Watson SD. Emotional functioning in children and adolescents with elevated depressive symptoms. J Psychopathol Behav Assess. 2011;33:335-45. https://doi.org/10.1007/s10862-011-9220-2.

61. Greuel JF, Reinhold N, Wenglorz M, Heinrichs N. Selbstberichtete Strategien zur Emotionsregulation bei Kindern und Jugendlichen mit psychischen Störungen [Self-reported emotion regulation strategies in children and adolescents with mental disorders]. Prax Kinderpsychol Kinderpsychiatr. 2015;64:368-85. https://doi.org/10.13109/prkk.2015.64.5.368.

62. Kessler H, Kammerer M, Hoffmann H, Traue HC. Regulation von Emotionen und Alexithymie: Eine korrelative Studie [regulation of emotions and alexithymia: a correlative study]. Psychother Psychosom Med Psychol. 2010; 60:169-74. https://doi.org/10.1055/s-0029-1234046.

63. van der Velde J, Gromann PM, Swart M, Wiersma D, de Haan L, Bruggeman $R$, Krabbendam L, Aleman A. Alexithymia influences brain activation during emotion perception but not regulation. Soc Cogn Affect Neurosci. 2014;10: 285-93. https://doi.org/10.1093/scan/nsu056.

64. Joormann J, Quinn ME. Cognitive processes and emotion regulation in depression. Depress Anxiety. 2014;31:308-15. https://doi.org/10.1002/da.22264.

65. Platt B, Waters AM, Schulte-Koerne G, Engelmann L, Salemink E. A review of cognitive biases in youth depression: attention, interpretation and memory. Cognit Emot. 2017;31:462-83. https:/doi.org/10.1080/02699931.2015.1127215.

66. Berking M, Wirtz CM, Svaldi J, Hofmann SG. Emotion regulation predicts symptoms of depression over five years. Behav Res Ther. 2014;57:13-20. https://doi.org/10.1016/j.brat.2014.03.003.

67. Joormann J, Stanton CH. Examining emotion regulation in depression: a review and future directions. Behav Res Ther. 2016;86:35-49. https://doi.org/ 10.1016/j.brat.2016.07.007.

68. Torres S, Guerra MP, Lencastre L, Miller K, Vieira FM, Roma-Torres A, Brandao I, Costa P. Alexithymia in anorexia nervosa: the mediating role of depression. Psychiatry Res. 2015;225:99-107. https://doi.org/10.1016/j. psychres.2014.10.023

69. Parling T, Mortazavi M, Ghaderi A. Alexithymia and emotional awareness in anorexia nervosa: time for a shift in the measurement of the concept? Eat Behav. 2010;11:205-10. https://doi.org/10.1016/j.eatbeh.2010.04.001.

70. Marchesi C, Bertoni S, Cantoni A, Maggini C. Is alexithymia a personality trait increasing the risk of depression? A prospective study evaluating alexithymia before, during and after a depressive episode. Psychol Med. 2008;38:1717-22. https://doi.org/10.1017/S0033291708003073.

71. Saarijarvi S, Salminen JK, Toikka TB. Alexithymia and depression: a 1-year follow-up study in outpatients with major depression. J Psychosom Res. 2001;51:729-33. https://doi.org/10.1016/50022-3999(01)00257-4.

72. Pollice C, Kaye WH, Greeno CG, Weltzin TE. Relationship of depression, anxiety, and obsessionality to state of illness in anorexia nervosa. Int J Eat Disord. 1997;21:367-76. https://doi.org/10.1002/(SICI)1098-108X(1997)21:4< 367::AID-EAT10>3.0.CO;2-W

73. Lennarz HK, Hollenstein T, Lichtwarck-Aschoff A, Kuntsche E, Granic I. Emotion regulation in action: use, selection, and success of emotion regulation in adolescents' daily lives. Int J Behav Dev. 2019;43:1-11. https:// doi.org/10.1177/0165025418755540

74. Seidel M, King JA, Ritschel F, Boehm I, Geisler D, Bernardoni F, Beck M, Pauligk S, Biemann R, Strobel A. Processing and regulation of negative emotions in anorexia nervosa: an fMRI study. Neuroimage Clin. 2018;18:1-8. https://doi.org/10.1016/j.nicl.2017.12.035.

75. Speranza M, Loas G, Wallier J, Corcos M. Predictive value of alexithymia in patients with eating disorders: a 3-year prospective study. J Psychosom Res. 2007;63:365-71. https://doi.org/10.1016/j.jpsychores.2007.03.008.

76. Ogrodniczuk JS, Piper WE, Joyce AS. Alexithymia as a predictor of residual symptoms in depressed patients who respond to short-term psychotherapy. Am J Psychother. 2004;58:150-61. https://doi.org/10.1176/appi. psychotherapy.2004.58.2.150.

77. Rowsell M, MacDonald DE, Carter JC. Emotion regulation difficulties in anorexia nervosa: associations with improvements in eating psychopathology. J Eat Disord. 2016;4:17. https://doi.org/10.1186/s40337-016-0108-0.

\section{Publisher's Note}

Springer Nature remains neutral with regard to jurisdictional claims in published maps and institutional affiliations.

Ready to submit your research? Choose BMC and benefit from:

- fast, convenient online submission

- thorough peer review by experienced researchers in your field

- rapid publication on acceptance

- support for research data, including large and complex data types

- gold Open Access which fosters wider collaboration and increased citations

- maximum visibility for your research: over $100 \mathrm{M}$ website views per year

At $\mathrm{BMC}$, research is always in progress.

Learn more biomedcentral.com/submissions 